\title{
Two different populations of Müller cells stabilize the structure of the fovea: an optical coherence tomography study
}

\author{
Andreas Bringmann • Jan Darius Unterlauft • Renate Wiedemann • \\ Thomas Barth · Matus Rehak • Peter Wiedemann (i)
}

Received: 3 April 2020/ Accepted: 20 June 2020/Published online: 6 July 2020

(C) The Author(s) 2020

\begin{abstract}
Purpose To document with spectral-domain optical coherence tomography the structural stabilization of the fovea and the sealing of outer macular defects by Müller cells.

Methods A retrospective case series of 45 eyes of 34 patients is described.

Results In cases of a cystic disruption of the foveola as in macular telangiectasia type 2 and vitreomacular traction, the Müller cell cone provides the structural stability of the fovea. In cases of a detachment or disruption of the Müller cell cone, e.g., in foveal pseudocysts, outer lamellar holes, and degenerative and tractional lamellar holes, Müller cells of the foveal walls may provide the structural stability of the fovea by the formation of a hyperreflective external limiting membrane (ELM) which bridges the holes in the central outer nuclear layer (ONL). Müller cells of the foveal walls and parafovea mediate the regeneration of the foveal architecture in cases of outer lamellar and full-thickness macular holes. The regeneration proceeds by a centripetal displacement of photoreceptor cell somata which closes the holes in the central ONL.
\end{abstract}

A. Bringmann - J. D. Unterlauft · R. Wiedemann .

T. Barth · M. Rehak · P. Wiedemann ( $\square)$

Department of Ophthalmology and Eye Hospital,

University of Leipzig, Liebigstrasse 10-14,

04103 Leipzig, Germany

e-mail: Peter.Wiedemann@medizin.uni-leipzig.de
The closure may be supported by the formation of a glial tissue band at the ELM which seals the hole.

Conclusions The Müller cell cone provides the foveal stability in cases of a cystic disruption of the foveola. The structural stability of the outer foveal layers is mainly provided by the Müller cells of the foveal walls and parafovea; these cells also mediate the regeneration of the outer fovea in cases of a defect of the central ONL.

Keywords Macular telangiectasia - Vitreomacular traction · Lamellar macular hole · Full-thickness macular hole $\cdot$ Fovea $\cdot$ Müller glia

$\begin{array}{ll}\text { Abbreviations } \\ \text { BCVA } & \text { Best-corrected visual acuity } \\ \text { ELM } & \text { External limiting membrane } \\ \text { EZ } & \text { Ellipsoid zone } \\ \text { FTMH } & \text { Full-thickness macular hole } \\ \text { HFL } & \text { Henle fiber layer } \\ \text { ILM } & \text { Internal limiting membrane } \\ \text { INL } & \text { Inner nuclear layer } \\ \text { IZ } & \text { Interdigitation zone } \\ \text { LHEP } & \text { Lamellar hole-associated epiretinal } \\ & \text { proliferation } \\ \text { NFL } & \text { Nerve fiber layer } \\ \text { ONL } & \text { Outer nuclear layer } \\ \text { OPL } & \text { Outer plexiform layer } \\ \text { RPE } & \text { Retinal pigment epithelium }\end{array}$


SD- Spectral-domain optical coherence

OCT tomography

\section{Introduction}

The structural stability of the fovea is provided by two populations of Müller glial cells: specialized cells which form the so-called Müller cell cone in the foveola, and Müller cells of the foveal walls and parafovea which have a characteristic $z$-shape because their outer processes run horizontally or obliquely through the Henle fiber layer (HFL) toward the foveal center [1-4]. The Müller cell cone may also contribute to the maintenance of the integrity of the foveal walls which surround the central foveola. A detachment of the horizontal layer of the Müller cell cone from the HFL/outer nuclear layer (ONL) in the foveola by anteroposterior traction exerted by the partially detached posterior hyaloid and the disruption of the vertical stalk of the Müller cell cone is often associated with an elevation of the inner layers of the foveal walls (nerve fiber layer [NFL] to the outer plexiform layer [OPL]); this may produce cystic cavities between the OPL and HFL, and within the inner nuclear layer (INL). Elevation of the inner layers of the foveal walls was shown to be implicated in the development of foveal pseudocysts, lamellar macular defects, and fullthickness macular holes (FTMH) [5-12].

The structural stability of the outer layers of the fovea (HFL, ONL) is suggested to be mainly provided by the outer processes of the Müller cells of the foveal walls and parafovea [4]. These processes surround the fibers and somata of photoreceptor cells, and constitute, together with the photoreceptor cells, the external limiting membrane (ELM) [3, 13]. Photoreceptor and Müller cells are tightly glued together in the HFL and ONL, and at the ELM [14, 15]. At the ELM, Müller cells contain contractile rings of filamentous actin which enclose the photoreceptors; these rings are associated with the junctions between Müller and photoreceptor cells and form a structural meshwork in which the photoreceptors are embedded [16]. The spatial arrangement of the Müller cell processes in the central ONL and the morphology of lamellar holes without disruption of the outer retinal layers may suggest that Müller cells of the foveal walls stabilize the architecture of the ONL, especially near and at the ELM. The stalk of the Müller cell cone does not contribute to the formation of the ELM because the cells of the Müller cell cone have no direct contact to photoreceptor cells $[4,13]$; this may ensure that the central ELM remains intact after a disruption of the stalk of the Müller cell cone.

Müller cells of the foveal walls and parafovea are also implicated in the regeneration of the outer retinal structure after surgical or spontaneous closure of FTMH [17-19]. Following the drop of the elevated inner layers of the foveal walls, which allows a reattachment of the outer retina to the retinal pigment epithelium (RPE), the remaining gaps in the central ONL and ELM are closed by a centripetal displacement of the photoreceptor cell somata likely mediated by a concentric contraction of the outer processes of the Müller cells of the foveal walls [18]. It is unclear whether this Müller cell-mediated regeneration of the outer retina is also observed in other types of outer retinal defects, e.g., outer lamellar holes [7]. It was recently described that the spontaneous closure of an outer lamellar hole in a patient with macular telangiectasia type 2 started as bridging at the level of the ELM and the outer part of the ONL; the authors suggested that extension or proliferation of Müller cells is the main mechanism for this phenomenon [20]. Here, we describe that one mode implicated in the structural stabilization of the outer fovea after disruption of the central ONL and ELM is the formation of a hyperreflective glial tissue band at the ELM which bridges holes in the outer retina. Cases of a tractional disruption of the Müller cell cone, foveal (pseudo)cysts, degenerative, tractional, and outer lamellar holes, and FTMH are included in the study. A FTMH develops by a disruption of both the Müller cell cone and the ELM in the foveola. An outer lamellar hole is characterized by a detachment of the inner Müller cell layer from the HFL/ONL and a large pseudocyst in the foveola which is associated with a disruption of the ELM and a dehiscence of the central ONL [7]. An outer lamellar hole often represents an early stage of FTMH formation [7, 12, 21]. In addition, we describe various cases of macular telangiectasia type 2 which are characterized by a cystic degeneration of the foveola due to the paracentral loss of photoreceptor cells $[22,23]$; in these cases, the shape of the central fovea is maintained by the Müller cell 
cone because no tractions are present which detach or tear the cone.

\section{Methods}

This retrospective study followed the ethical standards of the Declaration of Helsinki for research involving human subjects. The patients were referred to the Department of Ophthalmology, University of Leipzig, Germany, between February 2008 and September 2019. Thirty one patients with different types of partial-thickness macular defects and three patients with surgical closure of a FTMH were included in the study. Cross-sectional images of the macular area were obtained with spectral-domain optical coherence tomography (SD-OCT; Spectralis, Heidelberg Engineering, Heidelberg, Germany). Best-corrected visual acuity (BCVA) was determined with a Snellen chart and is given in decimal units.

All patients were Caucasians. SD-OCT images of the macular regions of both eyes of 6 patients with

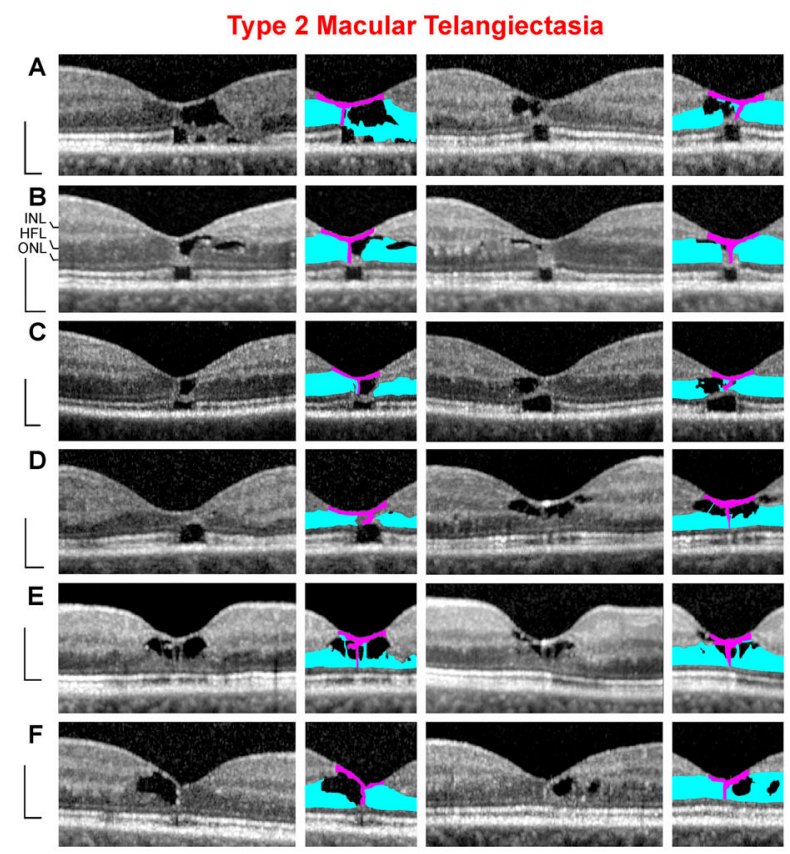

Fig. 1 Müller cell cone provides the stability of the foveal center in cases of cystic disruption of the foveola. a-f Macular telangiectasia type 2 . The images show linear scans through the fovea and parafovea in the left (left side) and right eyes (right side) of 6 patients. $\mathbf{g}-\mathbf{k}$ Vitreomacular traction. The images show linear scans through the fovea and parafovea in the left (left side) and right eyes (right side) of 5 patients. The smaller macular telangiectasia type 2 were investigated (Fig. 1a-f; 4 women, 2 men; mean \pm S.D. age, $59.7 \pm 6.7$ years; range $49-68$ years). The mean BCVA was $0.73 \pm 0.21$ (range, 0.4-1.0). SD-OCT scans of 5 further women showed vitreomacular traction without disruption of the Müller cell cone in one or both eyes (Fig. 1g-k; mean age, $68.6 \pm 14.3$ years; range, $45-83$ years; mean BCVA of the affected eyes, $0.55 \pm 0.21$, range $0.3-1.0$ ). SDOCT scans through the fovea of 7 subjects (mean age, $65.6 \pm 14.7$ years; range, 48-81 years) showed curved hyperreflective structures in the outer retina (Fig. 2). In addition, 13 patients with different types of tractionally induced macular defects in one eye were investigated (Fig. 3a-m; 9 women, 4 men; mean age, $67.4 \pm 17.7$ years, range $16-86$ years). The BCVA of the eyes with macular defects ranged from 0.3 to 0.9 (mean, $0.60 \pm 0.17$ ).

SD-OCT images recorded in one eye of 6 patients revealed the presence of an outer lamellar hole (Fig. 4a-f; 5 women, 1 man; mean age, $65.6 \pm 6.3$ years, range $55-72$ years). The mean

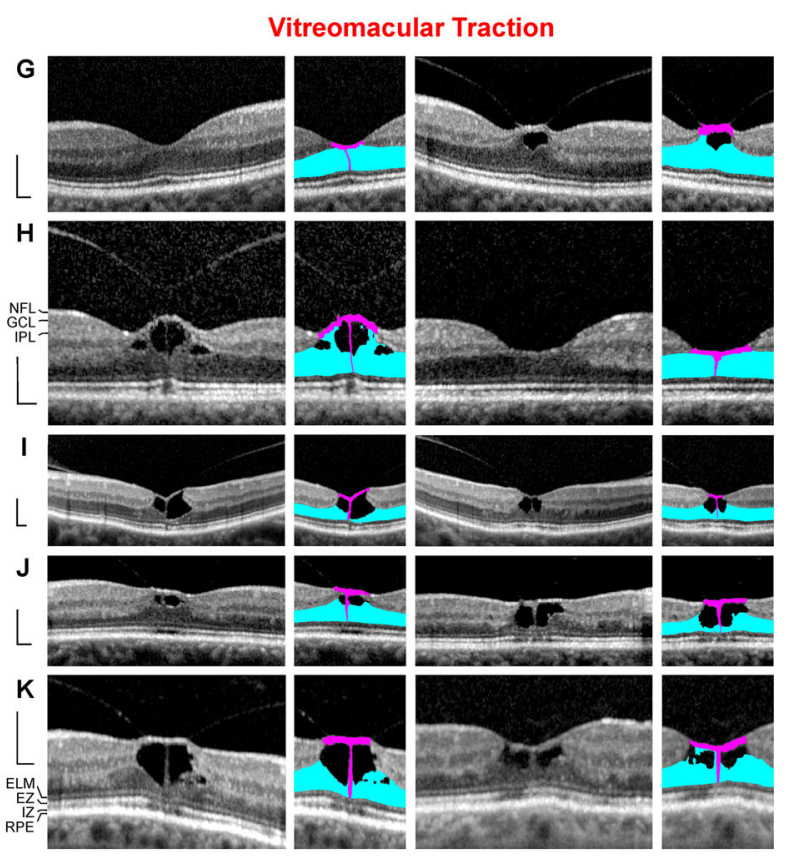

images beside the scans show the Müller cell cone in pink and the Henle fiber (HFL)/outer nuclear layers (ONL) of the fovea in blue. Scale bars, $200 \mu \mathrm{m}$. ELM, external limiting membrane; EZ, ellipsoid zone; GCL, ganglion cell layer; INL, inner nuclear layer; IPL, inner plexiform layer; IZ, interdigitation zone; NFL, nerve fiber layer; OPL, outer plexiform layer; RPE, retinal pigment epithelium 


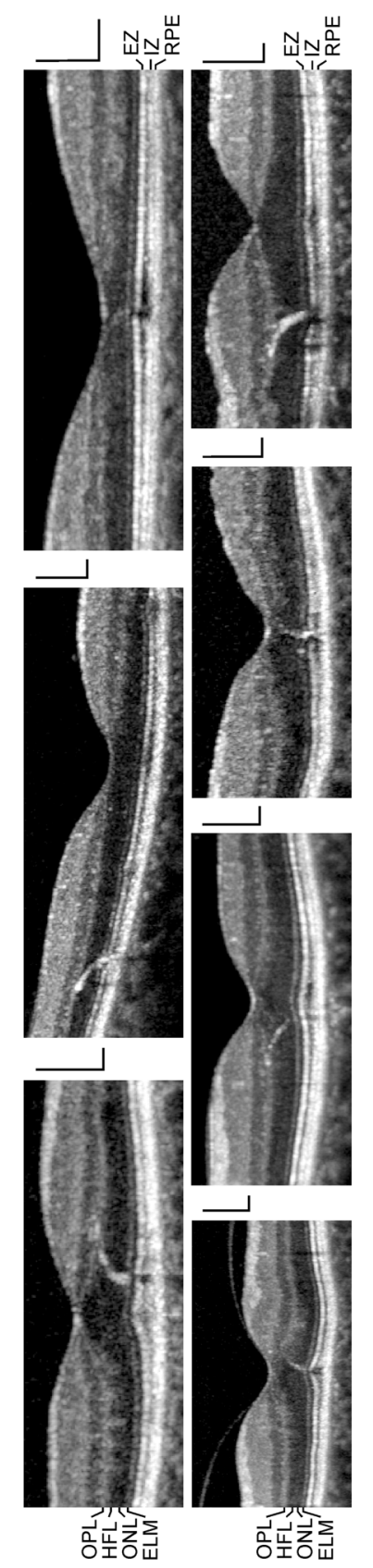

BCVA of these eyes was $0.38 \pm 0.17$ (range, 0.16-0.6). A 30-year-old woman had central visual disturbance and metamorphopsia in the right eye (BCVA, 0.16); SD-OCT showed serous macular detachment associated with a congenital optic disk pit (Fig. 5a, b). The foveal morphology regenerated spontaneously during the follow up, and BCVA improved to 0.6 .

The foveal regeneration after surgical closure of a FTMH with standard pars plana vitrectomy, internal limiting membrane (ILM) peeling, and SF6 tamponade in one eye of 3 women was also investigated (Fig. 6a-c; mean age, $71.0 \pm 7.8$ years, range 62-76 years). The mean BCVA of these eyes before surgery was $0.27 \pm 0.03$ (range, $0.25-0.30$ ).

\section{Results}

Macular telangiectasia type 2

Macular telangiectasia type 2 is characterized by a progressive bilateral cystic degeneration of the ONL in the fovea because of a loss of photoreceptor cells $[22,23]$. Because there are no tractional forces which disrupt the tissue integrity, the foveal contour remains normal; the shape of the foveal pit is maintained by the nondisrupted Müller cell cone which consists of the innermost horizontal layer of the foveola and the vertical stalk in the center of the foveola [4]. This is illustrated by the cases of macular telangiectasia type 2 in both eyes of 6 patients (Fig. 1a-f). Cystic cavities in the foveola mainly developed between the horizontal layer of the Müller cell cone and the HFL/ONL; the vertical stalk of the Müller cell cone prevented an elevation of the horizontal layer and thus maintained the shape of the foveal pit. The degeneration of photoreceptor cells was associated with a loss of the photoreceptor integrity, as indicated by the defects of the ellipsoid zone (EZ) and interdigitation zone (IZ) lines (Fig. 1a-c). In areas of a full degeneration of the photoreceptors, e.g., in the cases shown in Fig. 1b, c, glial tissues near and at the ELM formed by the outer processes of the Müller cells of the foveal walls contributed to the stabilization of the central foveal shape. 

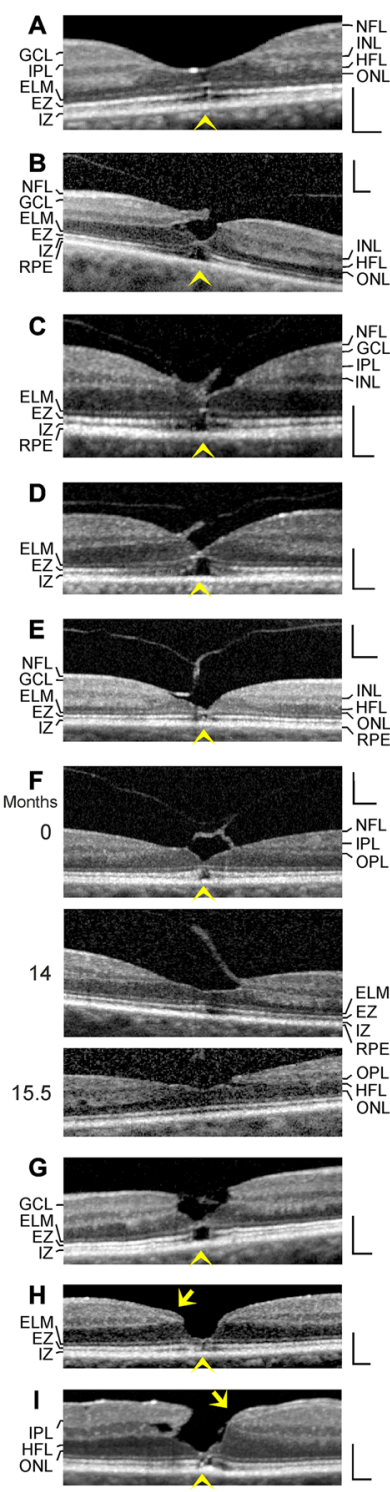

Fig. 3 Stability of the outer foveal structure may be supported by a hyperreflective glial tissue band at the external limiting membrane (ELM) (arrowheads) in different types of outer macular defects. The images show scans through the fovea and parafovea in eyes of different patients. a This fovea had a gap in the central outer nuclear layer (ONL) and a hyperreflective band which sealed the gap at the ELM. b-e Four cases of a tractional disruption of the Müller cell cone in the foveola. f Foveal regeneration after a tractional detachment and disruption of the Müller cell cone in the foveola. The months after the first visit (0) are indicated left of the images. Pars plana vitrectomy with internal limiting membrane peeling was performed 1.3 months after the first visit. $g$ Another case of a tractional disruption of

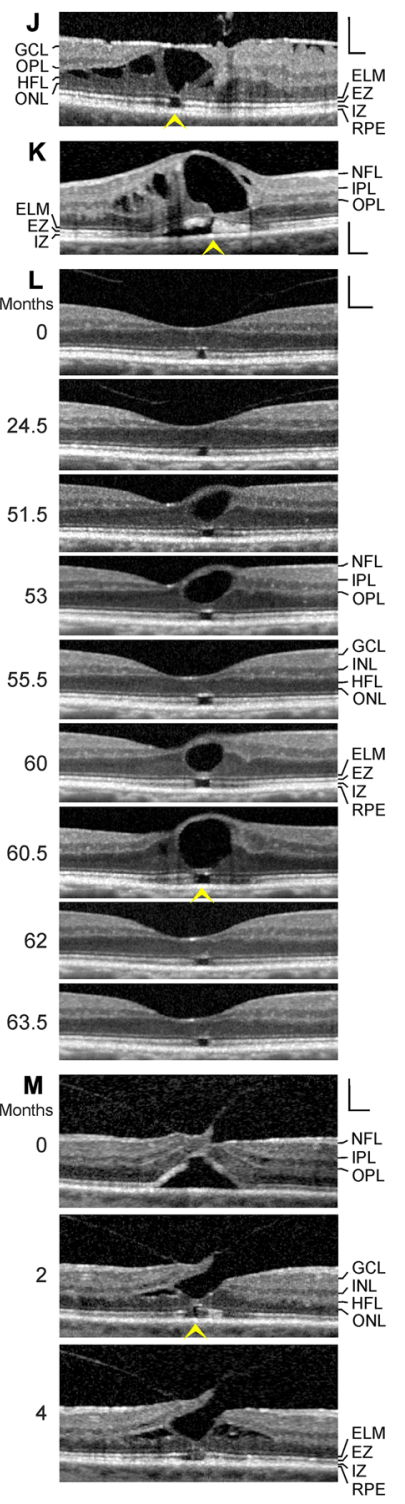

the Müller cell cone. h Impending degenerative lamellar hole. The arrow indicates lamellar macular hole-associated epiretinal proliferation (LHEP). i Degenerative lamellar hole. The arrow indicates LHEP. j Foveal pseudocyst. Note the presence of both epiretinal membranes and vitreofoveal adhesion. $\mathbf{k}$ Tissue disruption by a foveal cyst. I Multiple development and resolution of a cyst in the fovea. $\mathbf{m}$ Development of a tractional lamellar hole by anteroposterior traction exerted by the partially detached posterior hyaloid. Scale bars, $200 \mu \mathrm{m}$. EZ, ellipsoid zone; GCL, ganglion cell layer; HFL, Henle fiber layer; INL, inner nuclear layer; IPL, inner plexiform layer; IZ, interdigitation zone; NFL, nerve fiber layer; OPL, outer plexiform layer; RPE, retinal pigment epithelium 

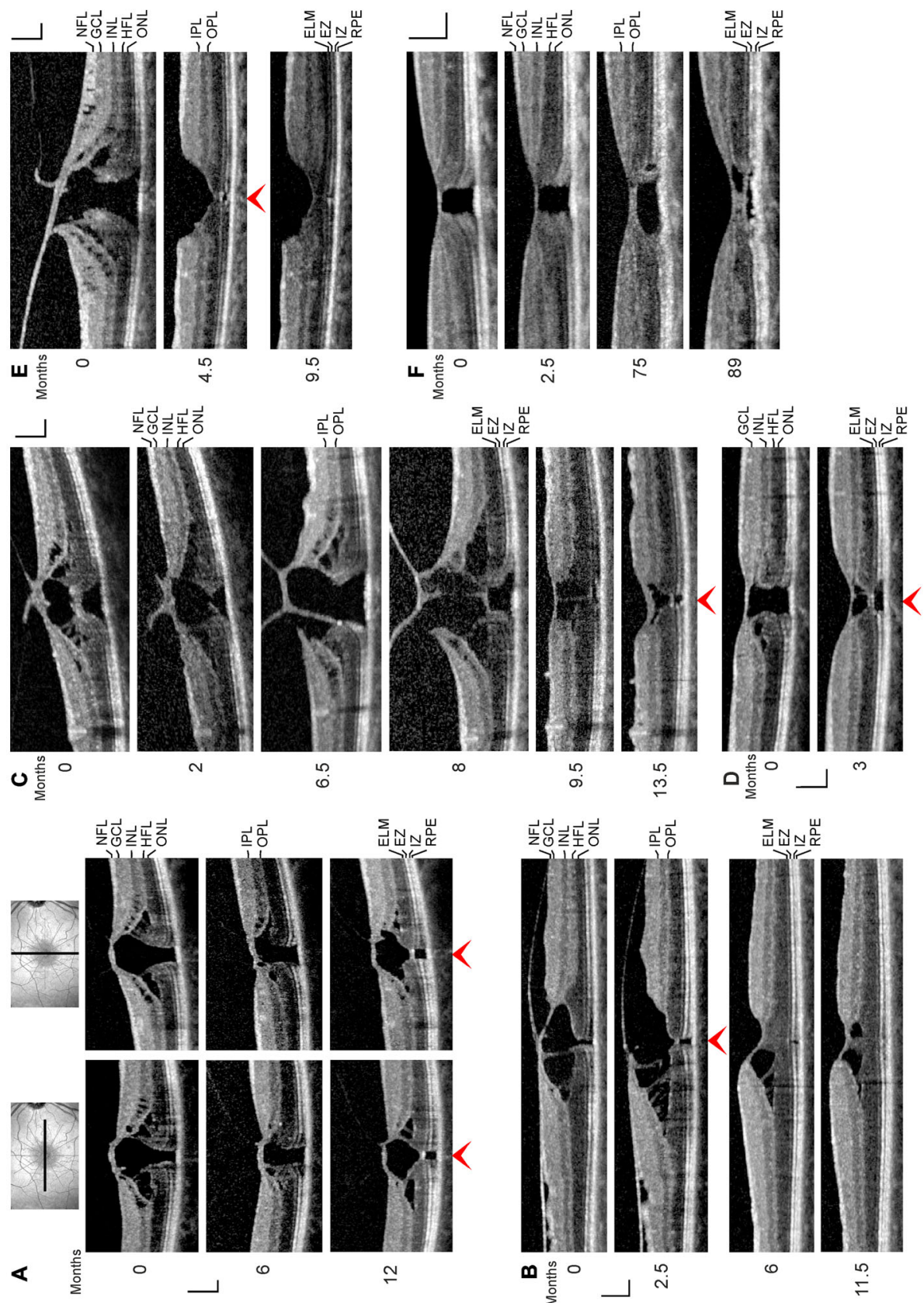

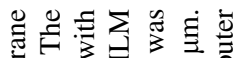

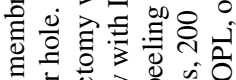

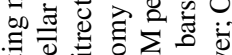

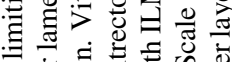

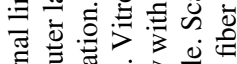
बे 0

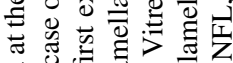

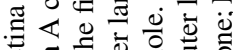

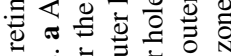

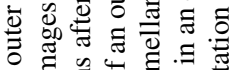
ठ․ำ

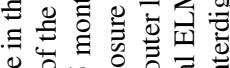

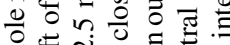

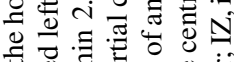

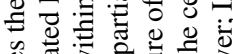

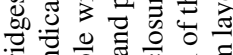

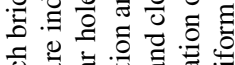

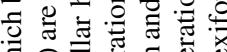

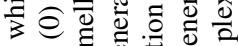
可

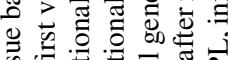
可记

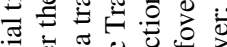
क力 o

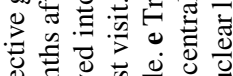

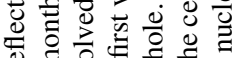

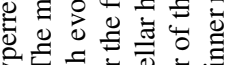

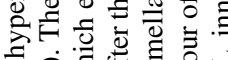

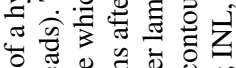

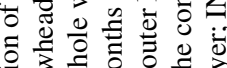

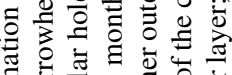

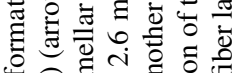

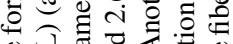

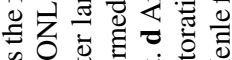

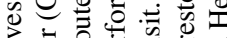

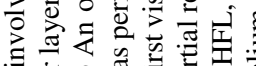

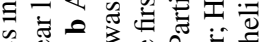

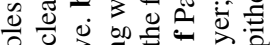

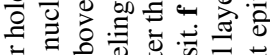

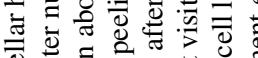

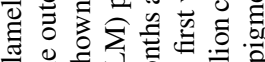
혼

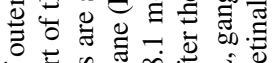

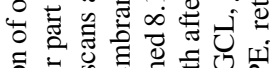

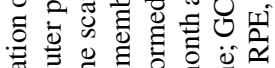

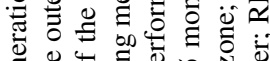

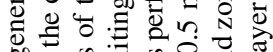

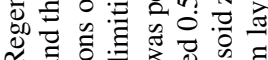

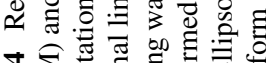

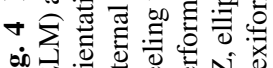

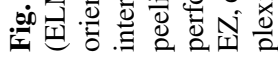



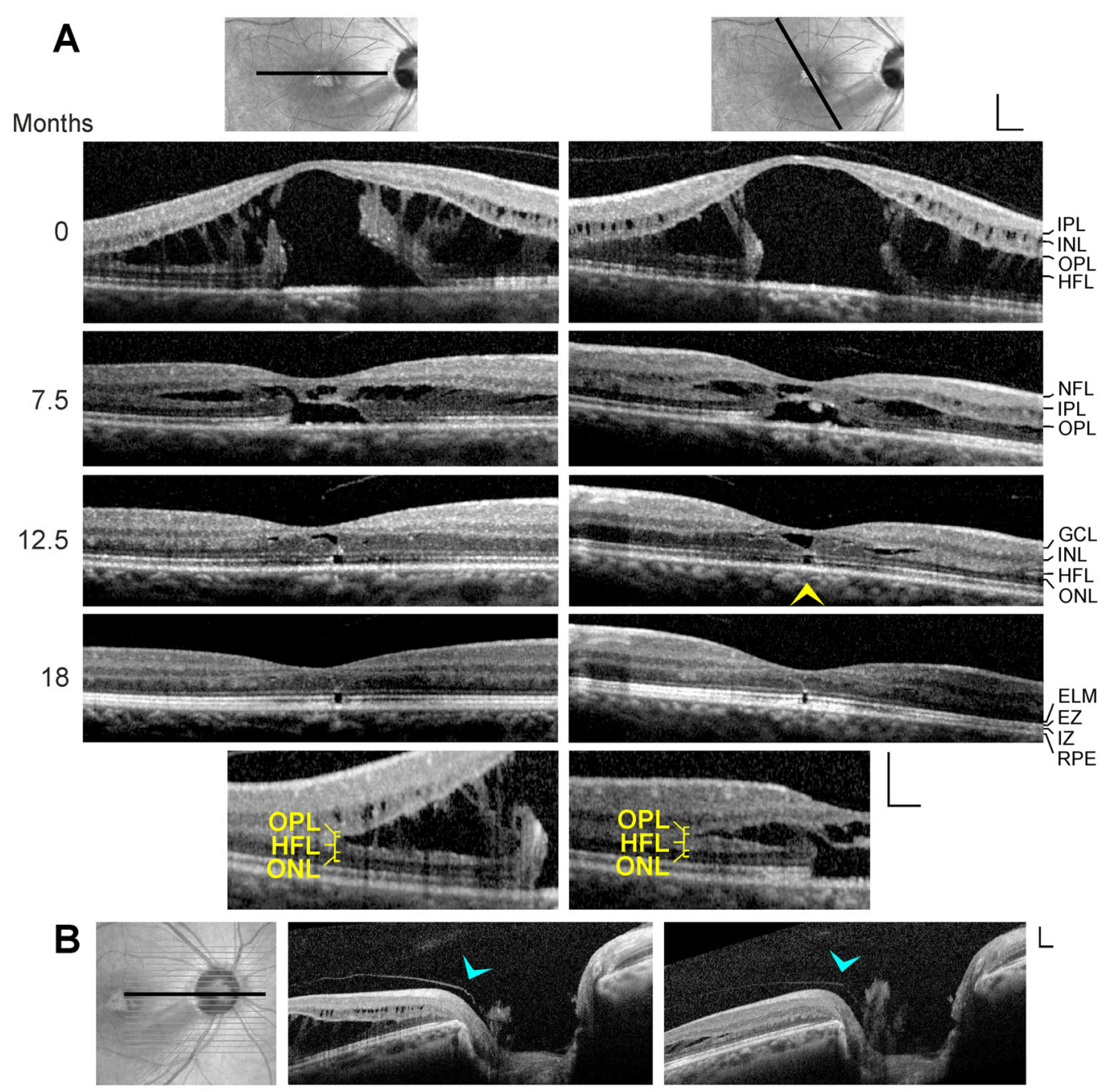

Fig. 5 Regeneration of the foveal morphology after spontaneous reattachment of the fovea in a case of serous macular detachment associated with a congenital optic pit. The images show linear scans through the fovea and parafovea (a) and the optic disk (b) of the right eye of a 30-year-old woman. a The months after the first visit (0) are indicated left of the images. The orientations of the scans are shown above. The yellow arrowhead indicates the hyperreflective glial tissue band which bridged the cyst in the foveola at the external limiting membrane (ELM) and the outer part of the outer nuclear layer (ONL). The

Vitreomacular traction without disruption of the Müller cell cone

The Müller cell cone also maintains the foveal integrity in cases of vitreofoveal traction; however, in these cases, the foveal contour is deteriorated. SDOCT scans of various eyes of 5 patients showed vitreomacular traction without a disruption of the smaller images below show scans through the fovea and parafovea obtained at (left) and 7.5 months after the first visit (right) at higher magnification. Note that the tissue split between the outer plexiform layer (OPL) and Henle fiber layer (HFL). b The scans were recorded during (left) and 7.5 months after the first visit (right). The blue arrowheads indicate vitreal adhesion at the prepapillary glial material. Scale bars, $200 \mu \mathrm{m}$. EZ, ellipsoid zone; GCL, ganglion cell layer; INL, inner nuclear layer; IPL, inner plexiform layer; IZ, interdigitation zone; NFL, nerve fiber layer; RPE, retinal pigment epithelium

Müller cell cone (Fig. 1g-k). This was associated with the formation of foveal pseudocysts due to a detachment of the horizontal layer of the Müller cell cone from the HFL/ONL in the foveola and an elongation or disruption of the vertical stalk of the cone. Foveal pseudocysts were also associated with an elevation of the inner layers of the foveal walls (NFL to OPL) and, in some cases, small cystic cavities between the OPL 


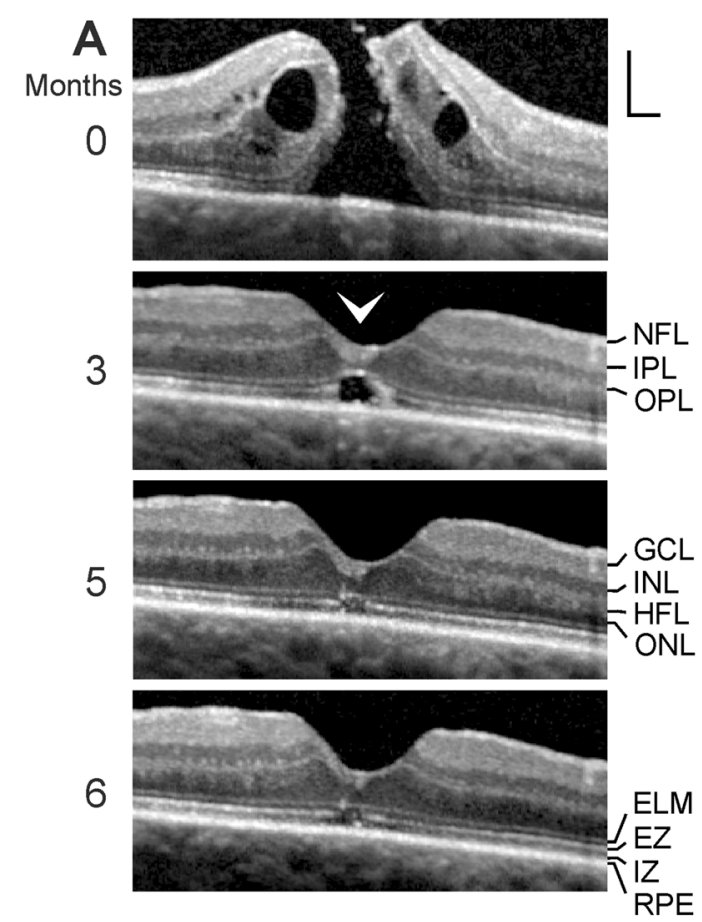

Fig. 6 Regeneration of the foveal shape after closure of a fullthickness macular hole (FTMH) may involve the formation of a glial tissue with medium reflectivity which seals the hole at the outer layers (arrowheads). The months after the first examination (0) are indicated left of the images. a-c Three cases of surgical closure of a FTMH. Vitrectomy with internal limiting membrane peeling was performed one (a), 1.5 (b), and

and HFL (Fig. 1h, k). In the fovea shown in Fig. 1I (left side), the central outer retina is stabilized only by a thin hyperreflective glial tissue near the ELM.

Figure $3 \mathrm{a}$ shows a fovea with a dehiscence of the central ONL (gap diameter, $40 \mu \mathrm{m}$ ) associated with defects of the EZ and IZ lines, indicating a loss of the photoreceptor integrity. The inner Müller cell layer of the foveola and the ELM were not disrupted. The ELM which bridged the gap in the ONL was hyperreflective.

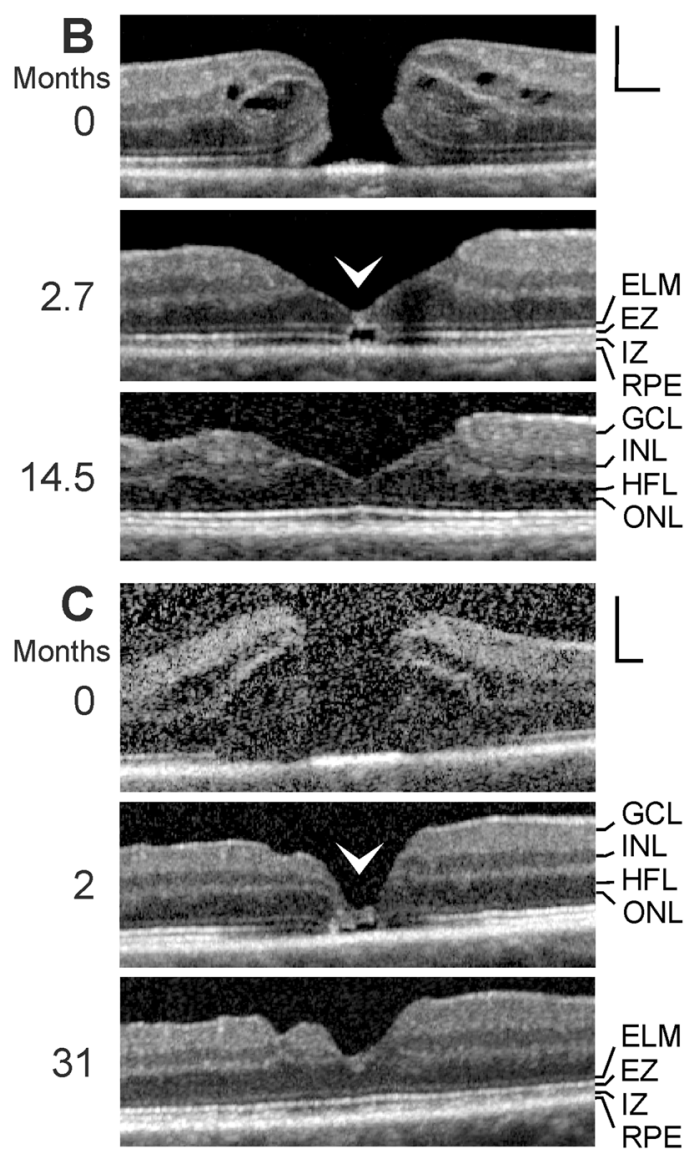

0.5 months (c) after the first visit, respectively. Scale bars, $200 \mu \mathrm{m}$. ELM, external limiting membrane; EZ, ellipsoid zone; GCL, ganglion cell layer; HFL, Henle fiber layer; INL, inner nuclear layer; IPL, inner plexiform layer; IZ, interdigitation zone; NFL, nerve fiber layer; ONL, outer nuclear layer; OPL, outer plexiform layer; RPE, retinal pigment epithelium

Spatial arrangement of the outer processes of the Müller cells of the foveal walls

A small focal loss of the photoreceptor integrity, as indicated by altered reflectivities of the EZ and IZ lines, may be associated with a curved hyperreflective structure which extends between the OPL and ELM (Fig. 2). The positions of the hyperreflective structures reflect the spatial arrangement of the photoreceptor cell fibers in the HFL and ONL. It could be that the hyperreflective structures are caused by a gliosis of the outer processes of the Müller cells of the foveal walls and parafovea induced by the local degeneration of the photoreceptor cells. These processes draw centripetally from the OPL toward the ELM, surround 
the photoreceptor cell axons in the HFL and the photoreceptor cell somata and outer processes in the ONL, and contribute to the formation of the ELM $[13,16]$.

Tractional disruption of the Müller cell cone

In cases of a tractional disruption of the Müller cell cone, Müller cells of the foveal walls and parafovea may provide the structural stability of the foveal center. Figure $3 \mathrm{~b}$ shows a fovea in which vitreofoveal traction caused a disruption of the connection between the inner Müller cell layer of the foveola and the temporal foveal wall. This was associated with a detachment of the inner Müller cell layer from the HFL/ONL in the foveola and a dehiscence of the central outer retina; the hole in the outer retina was sealed by the ELM and a tissue of medium reflectivity, likely composed of Müller cell processes. This sealing prevented the formation of a FTMH.

Figure $3 c$ shows another case of a tractional disruption of the Müller cell cone which was associated with a dehiscence of the central ONL; the gap in the ONL was filled by a hyperreflective tissue, likely representing the gliotic stalk of the Müller cell cone. The ELM which bridged the photoreceptor-free area in the central foveola was hyperreflective.

Figure $3 \mathrm{~d}-\mathrm{g}$ shows further cases of a detachment and disruption of the Müller cell cone in the foveola produced by traction exerted by the partially detached posterior hyaloid. In the cases shown in Fig. 3d, e, the detachment of the disrupted Müller cell cone resulted in a dehiscence of the central ONL. The foveal center was only stabilized by the ELM. The central borders of the ONL showed a curved shape, similar to the curved hyperreflective structures in the outer retina found in SD-OCT scans of foveas with small sites of lost photoreceptor integrity (Fig. 2). This suggests that the shape of the central ONL was stabilized by the outer processes of the Müller cells of the foveal walls, despite the dehiscence of this layer.

A similar morphology of the central fovea was observed in the case shown in Fig. 3f. Vitrectomy with ILM peeling was performed 1.3 months after the first visit. Despite the persistent detachment of the inner layer of the foveola, the thickness of the central ONL increased within 14 months after the first visit, likely by a centripetal displacement of photoreceptor cell somata; this was associated with a closure of the central defect of the EZ line. Another case of a disruption of the Müller cell cone and a dehiscence of the central ONL is shown in Fig. 3g; the photoreceptor-free area in the foveal center was bridged by the ELM.

Degenerative lamellar holes

A disruption of the Müller cell cone may also initiate the development of a degenerative lamellar hole. Many cases of degenerative lamellar holes show the presence of an atypical proliferative tissue at the NFL termed lamellar hole-associated epiretinal proliferation (LHEP) [24-28]. Figure $3 \mathrm{~h}$ shows a case of a disruption of the Müller cell cone which resulted in a large dehiscence of the ONL in the foveola; the foveal center kept together by the ELM. Defects of the EZ and IZ lines indicate that the center of the foveola was free of photoreceptors. This and the presence of LHEP at the vitreal side of the foveal walls may suggest that this case represents an impending degenerative lamellar hole. Figure $3 \mathrm{i}$ shows a case of a degenerative lamellar hole characterized by a dehiscence of the central ONL and the presence of LHEP; the photoreceptor-free area in the foveal center was bridged by a glial tissue at the level of the ELM and the outer part of the ONL.

Foveal (pseudo)cysts

Figure $3 \mathrm{j}$ shows a foveal pseudocyst which was likely produced by both contractile epiretinal membranes and vitreofoveal traction. The inner layer of the foveola was detached from the HFL/ONL and elevated; apparently, a hyperreflective epiretinal membrane laid over this layer. The elevation of the inner layer of the foveola produced an elevation of the inner layers of the foveal walls (NFL to OPL) and a schistic disruption of the tissue between the OPL and HFL. Thick bundles of Henle fibers traversed the schistic cavities; the position of the bundles suggests that the elevation of the inner layers of the foveal walls caused a stretching of Müller cells which exerted an oblique traction onto the outer retina resulting in a dehiscence of the ONL in the foveola, as previously suggested for the enlargement of FTMH [11]. The gap in the central ONL was photoreceptor-free and bridged by a hyperreflective ELM. 
Figure 3k shows a large edematous cyst in the fovea which was caused by branch retinal vein occlusion. The cyst produced an elevation of the inner layer of the foveola which was associated with an elevation of the inner layers of the foveal walls (NFL to IPL). The latter caused the cysts in the INL and a detachment of the central outer retina from the RPE. The large central cyst also produced a dehiscence of the ONL in the foveola; the gap in the ONL was bridged by the ELM.

Figure 31 shows a case of a twofold development and resolution of a cyst in the fovea. The scan recorded at the first visit shows vitreofoveal adhesion and an area in the foveola which was photoreceptor-free, as indicated by the EZ line defect. The ELM in the photoreceptor-free area was hyperreflective. Both episodes of foveal cyst formation were associated with a dehiscence of the central ONL. The gap in the central ONL was bridged by a hyperreflective band at the ELM and the outer part of the ONL. Thereafter, the gap in the central ONL completely closed, likely by a centripetal displacement of photoreceptor cell somata.

\section{Tractional lamellar hole}

Figure $3 \mathrm{~m}$ shows a case of a development of a tractional lamellar hole. The hole was produced by anteroposterior traction exerted by the partially detached posterior hyaloid. The traction caused a detachment and elevation of the central fovea from the RPE. Within 2 months after the first visit, the connection between the inner layer of the foveola and a foveal wall was disrupted; this allowed the drop of this wall while the inner layers of the opposite wall remained elevated. The reattachment of the central outer layers at the RPE was associated with a schistic splitting between the OPL and HFL of the foveal walls. The tractional forces also produced a dehiscence of the central ONL; the gap in the central ONL was sealed by the hyperreflective ELM and a tissue band of medium reflectivity, likely composed of Müller cell processes. The gap in the central ONL closed between 2 and 4 months, likely by a centripetal displacement of photoreceptor cell somata.

Outer lamellar holes

Outer lamellar holes are characterized by a large pseudocyst in the foveola which causes a detachment of the inner foveolar layer. The elevation of the inner layer is associated with an elevation of the inner layers of the foveal walls (NFL to OPL) which causes an oblique stretching and straightening of the Müller cells of the foveal walls that transmit the tension to the outer retina. This produces a centrifugal displacement of the central ONL and photoreceptors resulting in a disruption of the ELM and a hole in the outer retina [7, 11].

Figure 4a shows an outer lamellar hole which was produced by anteroposterior traction exerted by the partially detached posterior hyaloid. Between 6 and 12 months after the first examination, the diameter of the hole in the outer retina decreased from 270 to $160 \mu \mathrm{m}$. This was associated with the formation of a hyperreflective tissue band which bridged the hole at the ELM and the outer part of the ONL. Figure $4 \mathrm{~b}$ shows a small outer lamellar hole (diameter, $75 \mu \mathrm{m}$ ) which was formed by traction exerted by epiretinal membranes. Within 2.5 months after the first visit, a tractional lamellar hole was formed by the disruption of the inner layer of the foveola and the formation of a hyperreflective glial tissue band which sealed the hole in the outer retina at the ELM and the outer part of the ONL. After vitrectomy with ILM peeling performed 2.6 months after the first examination, the foveal morphology regenerated partially. The hole in the central ONL was closed after 6 months, and the defects of the EZ and IZ lines were closed 11.5 months. The ELM in front of the EZ and IZ lines defects was hyperreflective (6 months). The hyperreflectivity disappeared with the closure of the EZ and IZ line defects (11.5 months).

The SD-OCT scans in Fig. 4c show another case of a tractional development and partial closure of an outer lamellar hole. Between 6.5 and 8 months after the first visit, the central ELM regenerated. Pars plana vitrectomy with ILM peeling performed 8.1 months after the first visit removed the vitreofoveal traction which resulted in a drop of the elevated foveal walls associated with a reattachment of the central photoreceptors at the RPE. The diameter of the hole in the outer retina decreased from 270 to $120 \mu$ m between 8 and 9.5 months. The ELM which bridged the hole in the outer retina was hyperreflective. The foveal shape regenerated further between 9.5 and 13.5 months. The diameter of the outer retinal hole decreased to $110 \mu \mathrm{m}$, and the hole was bridged by a hyperreflective band at the ELM and the outer part of the ONL. In the case of an outer lamellar hole shown in Fig. 4d, the cystic 
cavities in the foveal walls resolved within 3 months after the first visit; this was associated with a drop of the elevated inner layers of the foveal walls and the central ONL, and a decrease in the diameter of the hole in the outer retina from 290 to $200 \mu \mathrm{m}$. The hole in the outer retina was sealed by a hyperreflective tissue band at the ELM and the outer part of the ONL.

The SD-OCT scans in Fig. 4e show a further example of a tractional generation and surgical closure of an outer lamellar hole. The removal of the vitreofoveal traction by vitrectomy with ILM peeling performed 0.5 month after the first visit resulted in a resolution of the cystic cavities in the foveal walls which allowed a drop of the elevated inner layers of the walls and a reattachment of the central outer retina at the RPE (4.5 months). The hole in the central outer retina was sealed by a hyperreflective ELM and a tissue of medium reflectivity, likely composed of Müller cell processes. Between 4.5 and 9.5 months, the central ONL thickened, likely by a centripetal displacement of photorecptor cell somata; this was associated with a decrease in the diameter of the central photoreceptor-free area and a disappearance of the hyperreflectivity of the ELM.

Figure 4f shows an outer lamellar hole without cystic cavities in the foveal walls. There was a dehiscence of the central ONL associated with defects of the ELM, EZ, and IZ lines. Between 2.5 and 75 months after the first examination, the ELM in the foveal center regenerated; the space between the inner layer of the Müller cell cone and the ELM was filled by a tissue of medium reflectivity, likely composed of Müller cells. The central ONL was not displaced toward the foveal center. In the further course, the distance between the central ELM and the RPE decreased (perhaps by a horizontal contraction of the ELM); this was associated with a partial restoration of the foveal shape, i.e., a thickening of the foveal center and a deepening of the foveal pit. However, the foveal center did not contain an ONL and photoreceptors and was composed of cystic spaces and a glial tissue of medium reflectivity.

Serous macular detachment

Figure 5b shows a case of a congenital optic pit associated with serous macular detachment (Fig. 5a). The foveal shape resembled that of a large outer lamellar hole with a high elevation of the inner layers of the foveal walls (NFL to OPL) which produced a schisis between the OPL and HFL; the detached, nondisrupted inner layer of the foveola kept the elevated foveal walls together. Bundles of Henle fibers traversed the schistic cavities between the OPL and HFL. The high elevation of the foveal walls also caused a disruption and elevation of the central outer retina; the ONL and photoreceptors were detached from the RPE and centrifugally displaced toward the foveal walls which produced a broad horizontal gap in the ONL (diameter, $850 \mu \mathrm{m}$ ) and wide defects of the central ELM, EZ, and IZ lines. The detachment of the central ONL apparently resulted from an oblique anterior traction exerted by the Müller cells of the foveal walls onto the central photoreceptor cells [11].

During the next 18 months, the foveal morphology regenerated spontaneously (Fig. 5a). Within 7.5 months, the elevated central fovea dropped down; this was associated with a considerable decrease in the size of the schistic cavities and a reattachment of the ONL and photoreceptors at the RPE in the foveal walls. However, the central fovea contained cystic spaces without an ONL and photoreceptors; there was a relatively wide area which was photoreceptor-free (diameter, $540 \mu \mathrm{m}$ ). The hyperreflective external layer of the foveola represents the regenerated ELM. Between 7.5 and 12.5 months, the gap in the central ONL closed by a centripetal displacement of the ONL of the foveal walls; this was associated with a decrease in the distance between the central hyperreflective ELM and the RPE. Between 12.5 and 18 months, the gap in the central ONL fully closed. There remained a small photoreceptor-free area which was associated with a hyperreflective ELM and a curved hyperreflectivity in the ONL. The latter may indicate that the outer processes of the Müller cells of the foveal walls were gliotic in this area.

Foveal regeneration after surgical closure of a FTMH

The regeneration of the foveal architecture after the closure of FTMH may involve the formation of a glial tissue which seals the hole at the outer layers. The FTMH shown in Fig. 6a closed within 2 months after surgery (3 months after the first examination). The closure was associated with a resolution of the cystic cavities between the OPL and HFL, and within the INL; this allowed a drop of the elevated inner layers of 

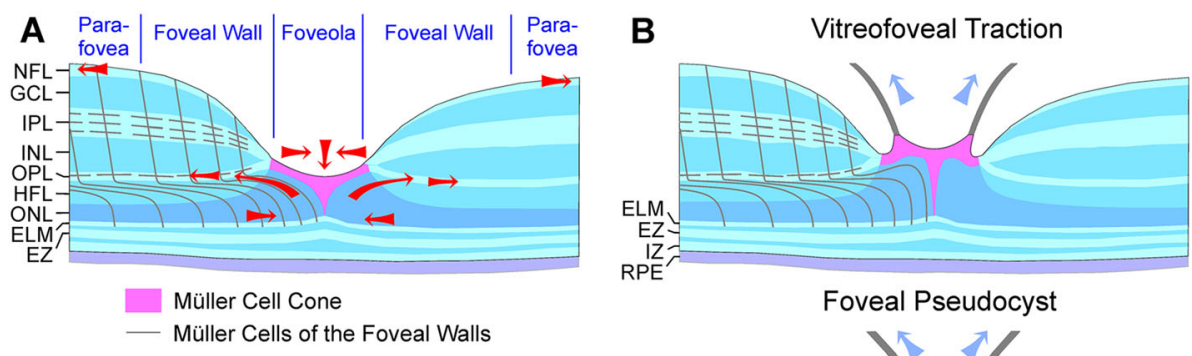

RPE

Foveal Pseudocyst

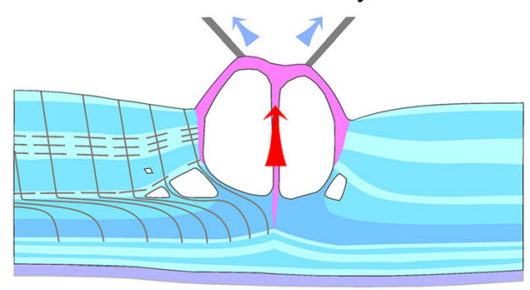

Outer Lamellar Hole

\section{E Disruption of the Müller Cell Cone}
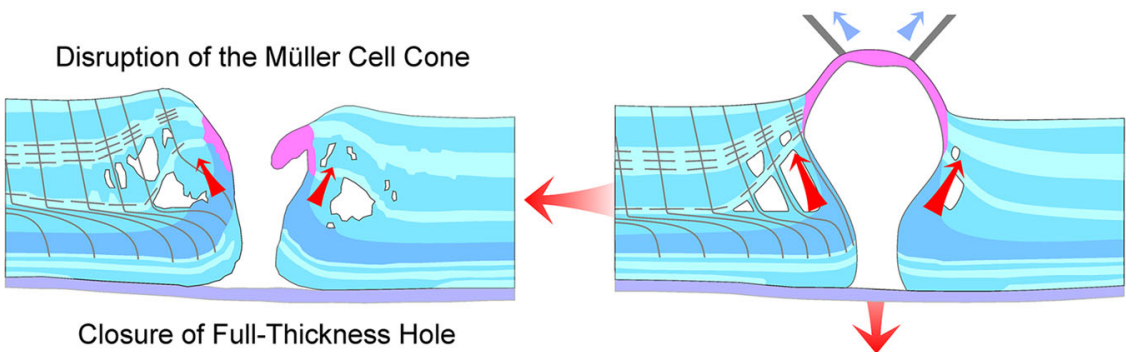

F Closure of Full-Thickness Hole

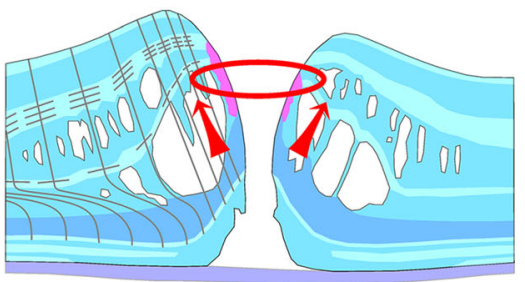

C

Sealing of Outer Lamellar Hole

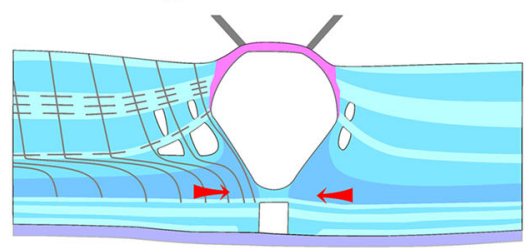

G

Regeneration of the Fovea

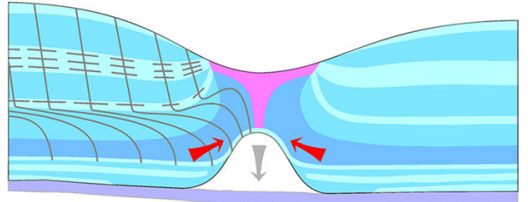

D

Regeneration of the Fovea
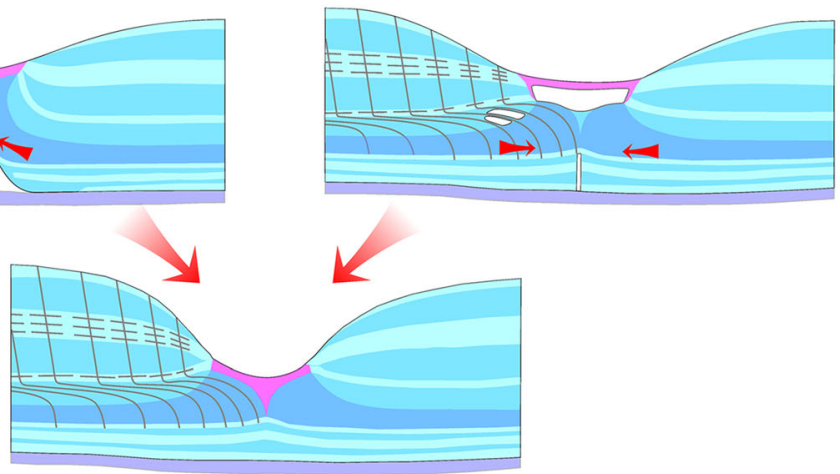
4Fig. 7 Hypothetical mechanisms of the formation and regeneration of outer lamellar and full-thickness macular holes. a Normal fovea. The Müller cell cone in the foveola is shown in pink. The black lines indicate the main and side processes of the $z$-shaped Müller cells of the foveal walls and parafovea. The arrows indicate traction vectors which are effective in the normal fovea. The fovea externa is formed by the elongated photoreceptor outer segments and is visible by the inclined courses of the external limiting membrane (ELM) and ellipsoid zone (EZ) lines. The horizontal layer of the Müller cell cone keeps the inner layers of the foveal walls together, and the vertical stalk of the Müller cell cone prevents an elevation of the inner layers of the foveal walls. The outer processes of the Müller cells of the foveal walls provide the structural stability of the outer layers, by tight-like junctions between these processes and photoreceptor cells, especially in the outer part of the outer nuclear layer (ONL), and by constitution of the ELM. Müller cells of the foveal walls may also regulate the slope of the ELM in the fovea externa. The side processes of the cells in the outer plexiform layer (OPL) are connected; horizontal contraction of these processes produces a centrifugal displacement of Henle fibers resulting in a steeper slope of the ELM in the fovea externa. b-d Formation (b) and closure (c) of outer lamellar holes, and regeneration of the foveal shape (d). The presumed Müller cell-mediated tissue movements are indicated by red arrows. Blue arrows indicate traction exerted by the posterior hyaloid. e-g Formation (e) and closure (f) of full-thickness macular holes, and regeneration of the foveal shape (g). GCL, ganglion cell layer; HFL, Henle fiber layer; INL, inner nuclear layer; IPL, inner plexiform layer; IZ, interdigitation zone; NFL, nerve fiber layer; RPE, retinal pigment epithelium

the foveal walls and a reattachment of the outer retina at the RPE. However, the central fovea remained elevated and did not contain an ONL and photoreceptors, but was filled by a tissue with medium reflectivity, likely composed of Müller cells. The ELM below this tissue was hyperreflective. Between 3 and 5 months, the gap in the central ONL closed, likely by a centripetal displacement of photoreceptor cell somata. This was associated with a drop of the central fovea and a decrease in the size of the photoreceptorfree area. During the next month, the foveal morphology did not alter, with the exception of a disappearance of the hyperreflectivity of the central ELM. There remained a small photoreceptor-free area in the foveal center, as indicated by the defect of the EZ line. The BCVA of this eye improved from 0.25 before to 1.0 after surgery.

The FTMH shown in Fig. $6 \mathrm{~b}$ closed within 1.2 months after surgery (2.7 months after the first examination). The resolution of the cystic cavities in the foveal walls was associated with a reattachment of the central outer retina at the RPE. The central fovea did not contain an ONL and photoreceptors. The ELM, which spanned the photoreceptor-free area, was hyperreflective. The ONL-free foveal center was filled by a hyperreflective glial tissue. Between 2.7 and 14.5 months, the foveal shape regenerated; the gap in the central ONL closed which was associated with a thickening of the foveal center, a disappearance of the photoreceptor-free area, and a regeneration of the fovea externa which is visible at the inclined courses of the ELM and EZ lines in the foveola. The BCVA of this eye improved from 0.3 before to 0.6 after surgery.

Figure $6 \mathrm{c}$ shows another case of a foveal regeneration after surgical closure of a FTMH; vitrectomy with ILM peeling was performed 0.5 month after the first visit. The resolution of the cystic cavities in the foveal walls was associated with a drop of the elevated inner layers of the foveal walls and a reattachment of the outer retina at the RPE ( 2 months). There was a relatively large gap in the central ONL (diameter, $300 \mu \mathrm{m}$ ) which was photoreceptor-free. The gap was filled by a tissue of medium reflectivity, likely composed of Müller cells. Between 2 and 31 months after the first examination, the gap in the central ONL closed, likely by a centripetal displacement of photoreceptor cell somata. The BCVA of this eye improved from 0.25 before surgery to 0.5 at the end of the examination period.

\section{Discussion}

In the normal fovea, the Müller cell cone provides the resistance of the foveal tissue against mechanical stress resulting from anteroposterior and tangential tractions (Fig. 7a). It was shown that there is a lifelong slow increase in the area of the foveal avascular zone associated with a decrease in the thickness of the foveal walls [29]. This suggests that there is a continuous centrifugal traction which widens the foveal pit. The traction is likely exerted by nerve fibers and astrocytes and is counteracted by the horizontal layer of the Müller cell cone which keeps the inner layers of the foveal walls together. The stiffness of the inner plexiform layer [4] may support an elevation of the inner layers of the foveal walls. This is prevented by the vertical stalk of the Müller cell cone in the center of the foveola. Anteroposterior or tangential tractions which produce a detachment 
and elevation of the horizontal layer of the Müller cell cone, associated with an elongation or disruption of the stalk of the Müller cell cone, may also produce an elevation of the inner layers of the foveal walls which is often associated with a schistic tissue disruption between the OPL and HFL (Figs. 1h, 3j, 4a-c, 7b).

The present data may suggest that the Müller cell cone provides the foveal stability in cases of a cystic disruption of the foveola. In cases of a central photoreceptor degeneration without vitreomacular traction which may detach or tear the Müller cell cone as in macular telangiectasia type 2 , the foveal contour remains normal (Fig. 1a-f). In cases of vitreomacular traction which detach the horizontal layer of the Müller cell cone from the HFL/ONL in the foveola, the foveal contour is altered (Fig. 1g-k). The detachment of the Müller cell cone from the HFL/ ONL was explained by the fact that there are no cellular connections between the cells of the Müller cell cone and the outer processes of the Müller cells of the foveal walls which envelop the somata and fibers of the photoreceptor cells in the HFL/ONL $[4,13]$. The outer layers of the foveola (HFL, ONL) were suggested to be structurally stabilized by the outer processes of the Müller cells of the foveal walls and parafovea, via a centripetal traction at the ELM and the outer part of the ONL and a centrifugal traction on the Henle fibers resulting from a horizontal contraction of Müller cell side processes in the OPL (Fig. 7a) [4]. The finding that, after a tractional disruption of the Müller cell cone, the shape of the ONL in the foveola may remain intact (with the exception of a widening of the central ONL; Fig. 3b, d-f) could be explained with the fact that the ONL is not stabilized by the Müller cell cone, but by the outer processes of the Müller cells of the foveal walls which also constitute (together with photoreceptor cells) the ELM (Fig. 2). The data may suggest that the horizontal layer of the Müller cell cone also counteracts the centrifugal pulling of the Henle fibers produced by the Müller cells of the foveal walls which may mediate the widening of the central ONL.

Macular telangiectasia type 2 was suggested to be caused by a dysfunction and/or degeneration of Müller cells; Müller cell dysfunction may produce the vascular symptoms and the degeneration of photoreceptors $[30,31]$. The finding that the foveal shape is maintained by the Müller cell cone in cases of macular telangiectasia type 2 (Fig. 1a-f) suggests that the loss of photoreceptor cells is associated with a degeneration of the outer processes of Müller cells of the foveal walls which surround the photoreceptor cells in the central outer retina $[4,13]$ but not by a dysfunction/ degeneration of the cells of the Müller cell cone. This assumption also fits with the facts that Müller cells of the foveal walls and parafovea, but not cells of the Müller cell cone (which lies within the foveal avascular zone), have contact to blood vessels [13] and that the Müller cell markers vimentin and glutamine synthetase are reduced in the fovea of a macular telangiectasia type 2 patient compared to control tissues while the expression of glial fibrillary acidic protein (GFAP) is normal in the macular region $[30,31]$. Glutamine synthetase is normally expressed by the Müller cells of the foveal walls and parafovea but at low level in the Müller cell cone (because the Müller cell cone has no contact to retinal synapses), whereas GFAP is expressed by the Müller cell cone and, at lower level, by the outer processes of the Müller cells of the foveal walls [4, 32, 33]. In addition, the previously published finding that markers for the ELM are lost in the central macula of the macular telangiectasia type 2 patient [31] suggests a dysfunction and/or degeneration of the Müller cells of the foveal walls and parafovea because cells of the Müller cell cone likely do not contribute to the formation of the ELM because they have no direct contact to the photoreceptor cells [13].

In various types of foveal defects, which are characterized by a detachment and/or a disruption of the Müller cell cone, Müller cells of the foveal walls may support the structural stability of the foveal center (Fig. 3b, d-m). These cells may also seal holes in the central outer retina by the formation of a tissue band which bridges the holes at the ELM (Fig. 4a, c, d) and may mediate the regeneration of the central fovea in cases of outer and tractional lamellar holes (Figs. 4b, $\mathrm{e}, 5 \mathrm{a})$. It was shown that the regeneration of the foveal structure after surgical or spontaneous closure of FTMH may include a centripetal displacement of the central ONL, likely caused by radial forces created by the contraction of Müller cell processes in the outer part of the ONL and at the ELM which drag the photoreceptor cell somata centrally [18, 19]. The Müller cell-mediated centripetal displacement of the photoreceptor cell somata results in a closure of the central photoreceptor-free area and an increase in the photoreceptor density in the regenerated foveola. A 
similar centripetal displacement of the central ONL was found in the cases of the regeneration of the foveal structure after surgical closure of FTMH described in this study (Fig. 6a-c). In the case of the tractional lamellar hole shown Fig. 4b, the hole in the central outer retina was likely closed by a centripetal displacement of the photoreceptor cell somata. In the cases of outer lamellar holes (Fig. 4a, c, d) and the regeneration of a serous macular detachment (Fig. 5a), the diameter of the hole in the outer retina decreased time dependently by a centripetal displacement of the ONL.

A tractional disruption of the Müller cell cone is often associated with a dehiscence of the central ONL; the foveal center is only stabilized by the ELM (Fig. 3c-f). The regeneration of the foveal center proceeds by a centripetal Müller cell-mediated displacement of photoreceptor cell somata which may occur despite the disruption of the Müller cell cone, as shown in Fig. 3f. It was shown that the closure of a FTMH can occur although the inner Müller cell layer of the foveola remains detached from the central ONL; in this mode of hole closure, the ONL is displaced centripetally, the hole closes only at the ELM, and a new Müller cell cone is not formed [9]. Furthermore, a regeneration of the central ELM and the foveal shape can also proceed without a centripetal displacement of the ONL, as shown in Fig. 4f.

Shortly after the closure of a FTMH, the central ONL displayed a gap and an absence of photorecpetors while the gap in the ELM was closed (Fig. 6a-c). The gap in the central ONL was filled by a tissue of medium reflectivity, likely Müller cells. On the other hand, in cases of outer lamellar holes, the holes in the outer retina were sealed by a hyperreflective tissue band at the ELM and the outer part of the ONL (Fig. 4a-d). Similar hyperreflective bands at the ELM, which sealed a hole in the central ONL, were found in different types of outer macular defects (Fig. 3a, d-j, m) and in the case of the foveal regeneration after serous macular detachment (Fig. 5a). It is likely that the tissue bands provide the structural stability of the outer retina when a hole in the central ONL is present. As suggested by the cases shown in Figs. $4 \mathrm{~b}$ and 5a, the tissue bands at the ELM may be also implicated in the regeneration of the regular structure of the outer retina; a contraction of the bands may support the centripetal displacement of the ONL which closes the central photoreceptor-free area. However, a new ELM can be also formed without a displacement of the ONL, as indicated by the case of an outer lamellar hole shown in Fig. 4f.

The cellular origin of the hyperreflective tissue bands at the ELM is unclear. The central fovea only contains Müller and photoreceptor cells [1, 4, 13]. Because the holes in the central ONL were associated with an absence of photoreceptors, as indicated by the defects of the EZ and IZ lines, the hyperreflective tissue bands which bridge the holes are formed by Müller cells. The tissue bands are formed at the outer part of the ONL and the ELM. The ELM is constituted by tight-like junctions between Müller cell processes and photoreceptor cells [14, 15]. Because the fibers and somata of the photoreceptor cells are surrounded by the outer processes of the Müller cells of the foveal walls $[4,13]$, it is likely that the hyperreflective tissue bands in the outer retina are formed by outgrowing processes of these cells. The hyperreflectivity of the bands is likely generated by light reflections at the outgrowing Müller cell processes which are optically dense due to an upregulation of glial intermediate filaments. Müller cell gliosis is known to be associated with an upregulation of intermediate filaments [34]; these filaments support the structural stabilization of the retina [3, 35-37].

In most cases described in this study, the formation of glial tissue bands which seal outer retinal holes at the ELM was associated with a narrowing of the hole by the Müller cell-mediated centripetal displacement of the ONL. It was shown that small FTMH with a diameter of less than $400 \mu \mathrm{m}$ may close spontaneously $[38,39]$. The finding that only small holes can close spontaneously was explained with the assumption that the distance of the Müller cell-mediated centripetal tissue movements is restricted to the diameter of the foveola (in the mean, about $350 \mu \mathrm{m}$ [40]) [18]. It is unclear whether the size of an outer lamellar hole plays a role in the sealing of the holes by a glial tissue band at the ELM. In the cases of outer lamellar holes presented in this study, the diameters of the holes ranged from 75 to $290 \mu \mathrm{m}$ before the formation of the tissue bands and from 40 to $200 \mu \mathrm{m}$ after the formation.

Figure $7 \mathrm{~b}-\mathrm{g}$ summarizes hypothetical mechanisms of the formation and closure of outer lamellar holes and FTMH. The tractional formation of a foveal pseudocyst results in a detachment and elevation of the inner Müller cell layer of the foveola associated with 
an elongation and subsequent disruption of the stalk of the Müller cell cone (Fig. 7b) [18]. The elevation of the inner layer of the foveola produces an elevation of the inner layers of the foveal walls which is associated with a cystic disruption of the tissue mainly between the OPL and HFL. The position of the Henle fiber bundles, which traverse the cystic cavities, may indicate that the Müller cells of the foveal walls are stretched which causes a shape alteration of the Müller cells from the $\mathrm{z}$-shape to a straight shape [11]. The stretched Müller cells were suggested to exert a traction onto the outer retina in an oblique anterior direction which causes a dehiscence of the central ONL [11] resulting in the formation of an outer lamellar hole (Fig. 7b). The hole is closed by two mechanisms: a centripetal displacement of the photoreceptor cell somata in the ONL mediated by a concentric contraction of Müller cell processes near and at the ELM, and the formation of a tissue band at the ELM by outgrowing Müller cell processes which bridges the hole (Fig. 7c, d). Contraction of the glial tissue bands may support the centripetal displacement of the photoreceptor cell somata. Tractional disruption of the Müller cell cone produces a FTMH from an outer lamellar hole (Fig. 7e). The hole is widened by the enlargement of edematous cysts in the foveal walls which further elevates the inner layers of the walls (Fig. 7f) [11, 41, 42]. The closure of FTMH was suggested to proceed by a concentric contraction of Müller cell side processes in the OPL (Fig. 7f) and the resolution of the edematous cysts in the foveal walls; the subsequent regeneration of the foveal shape proceeds via a Müller cell-mediated centripetal displacement of the photoreceptor cell somata in the ONL (Fig. 7g) [18].

In summary, the present data suggest that the Müller cell cone maintains the structure of the central fovea in cases of a cystic disruption of the foveola when no tractions are present which detach or disrupt the cone. Müller cells of the foveal walls may provide the stability and may mediate the regeneration of the outer fovea in cases of defects of the central ONL by two mechanisms: a centripetal displacement of the photoreceptor cell somata and the formation of a glial tissue band at the ELM and the outer part of the ONL which bridges the hole in the central ONL.

Acknowledgements Open Access funding provided by Projekt DEAL.
Open Access This article is licensed under a Creative Commons Attribution 4.0 International License, which permits use, sharing, adaptation, distribution and reproduction in any medium or format, as long as you give appropriate credit to the original author(s) and the source, provide a link to the Creative Commons licence, and indicate if changes were made. The images or other third party material in this article are included in the article's Creative Commons licence, unless indicated otherwise in a credit line to the material. If material is not included in the article's Creative Commons licence and your intended use is not permitted by statutory regulation or exceeds the permitted use, you will need to obtain permission directly from the copyright holder. To view a copy of this licence, visit http://creativecommons.org/licenses/by/4.0/.

Author's contribution $\mathrm{AB}$ and $\mathrm{PW}$ conceived and designed the research. JDU, RW, TB, and MR conducted experiments. $\mathrm{AB}$ and $\mathrm{PW}$ analyzed and interpreted the data. MR and PW supervised research personnel. AB: drafted the manuscript. JDU, RW, TB, MR, and PW made critical revision of the manuscript.

\section{References}

1. Yamada E (1969) Some structural features of the fovea centralis in the human retina. Arch Ophthalmol 82:151-159

2. Gass JDM (1999) Müller cell cone, an overlooked part of the anatomy of the fovea centralis: hypotheses concerning its role in the pathogenesis of macular hole and foveomacualr retinoschisis. Arch Ophthalmol 117:821-823

3. Reichenbach A, Bringmann A (2010) Müller cells in the healthy and diseased retina. Springer, New York

4. Bringmann A, Syrbe S, Görner K, Kacza J, Francke M, Wiedemann P, Reichenbach A (2018) The primate fovea: structure, function and development. Prog Retin Eye Res 66:49-84

5. Kishi S, Kamei Y, Shimizu K (1995) Tractional elevation of Henle's fiber layer in idiopathic macular holes. Am J Ophthalmol 120:486-496

6. Gaudric A, Haouchine B, Massin P, Paques M, Blain P, Erginay A (1999) Macular hole formation: new data provided by optical coherence tomography. Arch Ophthalmol 117:744-751

7. Spaide RF (2000) Closure of an outer lamellar macular hole by vitrectomy: hypothesis for one mechanism of macular hole formation. Retina 20:587-590

8. Haouchine B, Massin P, Gaudric A (2001) Foveal pseudocyst as the first step in macular hole formation: a prospective study by optical coherence tomography. Ophthalmology 108:15-22

9. Takahashi A, Nagaoka T, Ishiko S, Kameyama D, Yoshida A (2010) Foveal anatomic changes in a progressing stage 1 macular hole documented by spectral-domain optical coherence tomography. Ophthalmology 117:806-810

10. Gentile RC, Landa G, Pons ME, Eliott D, Rosen RB (2010) Macular hole formation, progression, and surgical repair: 
case series of serial optical coherence tomography and time lapse morphing video study. BMC Ophthalmol 10:24

11. Woon WH, Greig D, Savage MD, Wilson MCT, Grant CA, Mokete B, Bishop F (2015) Movement of the inner retina complex during the development of primary full-thickness macular holes: implications for hypotheses of pathogenesis. Graefes Arch Clin Exp Ophthalmol 253:2103-2109

12. Chung H, Byeon SH (2017) New insights into the pathoanatomy of macular holes based on features of optical coherence tomography. Surv Ophthalmol 62:506-521

13. Syrbe S, Kuhrt H, Gärtner U, Habermann G, Wiedemann P, Bringmann A, Reichenbach A (2018) Müller glial cells of the primate foveola: an electron microscopical study. Exp Eye Res 167:110-117

14. Omri S, Omri B, Savoldelli M, Jonet L, Thillaye-Goldenberg B, Thuret G, Gain P, Jeanny JC, Crisanti P, BeharCohen F (2010) The outer limiting membrane (OLM) revisited: clinical implications. Clin Ophthalmol 4:183-195

15. Matet A, Savastano MC, Rispoli M, Bergin C, Moulin A, Crisanti P, Behar-Cohen F, Lumbroso B (2015) En face optical coherence tomography of foveal microstructure in full-thickness macular hole: a model to study perifoveal Müller cells. Am J Ophthalmol 159:1142-1151

16. Del Priore LV, Lewis A, Tan S, Carley WW, Webb WW (1987) Fluorescence light microscopy of F-actin in retinal rods and glial cells. Invest Ophthalmol Vis Sci 28:633-639

17. Madreperla SA, Geiger GL, Funata M, de la Cruz Z, Green WR (1994) Clinicopathologic correlation of a macular hole treated by cortical vitreous peeling and gas tamponade. Ophthalmology 101:682-686

18. Bringmann A, Duncker T, Jochmann C, Barth T, Duncker GIW, Wiedemann P (2020) Spontaneous closure of small full-thickness macular holes: presumed role of Müller cells. Acta Ophthalmol 98:e447-e456

19. Bringmann A, Jochmann C, Unterlauft JD, Wiedemann R, Rehak M, Wiedemann P (2020) Different modes of foveal regeneration after closure of full-thickness macular holes by (re)vitrectomy and autologous platelet concentrate. Int $\mathrm{J}$ Ophthalmol 13:36-48

20. Nalci H, Batioglu F, Demirel S, Özmert E (2018) Spontaneous closure of macular hole in a patient with macular telangiectasia type 2. Retin Cases Brief Rep. https://doi.org/ 10.1097/icb.0000000000000812

21. Gass JDM (1995) Reappraisal of biomicroscopic classification of stages of development of a macular hole. Am J Ophthalmol 119:752-759

22. Yannuzzi LA, Bardal AM, Freund KB, Chen KJ, Eandi CM, Blodi B (2006) Idiopathic macular telangiectasia. Arch Ophthalmol 124:450-460

23. Ooto S, Hangai M, Takayama K, Arakawa N, Tsujikawa A, Koizumi H, Oshima S, Yoshimura N (2011) High-resolution photoreceptor imaging in idiopathic macular telangiectasia type 2 using adaptive optics scanning laser ophthalmoscopy. Invest Ophthalmol Vis Sci 52:5541-5550

24. Haouchine B, Massin P, Tadayoni R, Erginay A, Gaudric A (2004) Diagnosis of macular pseudoholes and lamellar macular holes by optical coherence tomography. Am J Ophthalmol 138:732-739

25. Witkin AJ, Ko TH, Fujimoto JG, Schuman JS, Baumal CR, Rogers AH, Reichel E, Duker JS (2006) Redefining lamellar holes and the vitreomacular interface: an ultrahigh- resolution optical coherence tomography study. Ophthalmology 113:388-397

26. Pang CE, Maberley DA, Freund KB, White VA, Rasmussen S, To E, Matsubara JA (2016) Lamellar hole-associated epiretinal proliferation. A clinicopathologic correlation. Retina 36:1408-1412

27. Govetto A, Dacquay Y, Farajzadeh M, Platner E, Hirabayashi K, Hosseini H, Schwartz SD, Hubschman JP (2016) Lamellar macular hole: two distinct clinical entities? Am J Ophthalmol 164:99-109

28. Haritoglou C, Tadayoni R, Hubschman JP (2019) Lamellar macular hole surgery: current concepts, future prospects. Clin Ophthalmol 13:143-146

29. Gong D, Zou X, Zhang X, Yu W, Qu Y, Dong F (2016) The influence of age and central foveal thickness on foveal zone size in healthy people. Ophthalmic Surg Lasers Imaging Retina 47:142-148

30. Powner MB, Gillies MC, Tretiach M, Scott A, Guymer RH, Hageman GS, Fruttiger M (2010) Perifoveal Müller cell depletion in a case of macular telangiectasia type 2. Ophthalmology 117:2407-2416

31. Powner MB, Gillies MC, Zhu M, Vevis K, Hunyor AP, Fruttiger M (2013) Loss of Müller's cells and photoreceptors in macular telangiectasia type 2. Ophthalmology 120:2344-2352

32. Nishikawa S, Tamai M (2001) Müller cells in the human foveal region. Curr Eye Res 22:34-41

33. Nishikawa S (2006) The pathology of Müller cells under different disease conditions. Neuroembryol Aging 4:61-75

34. Bringmann A, Iandiev I, Pannicke T, Wurm A, Hollborn M, Wiedemann P, Osborne NN, Reichenbach A (2009) Cellular signaling and factors involved in Müller cell gliosis: neuroprotective and detrimental effects. Prog Retin Eye Res 28:423-451

35. Reichenbach A (1989) Attempt to classify glial cells by means of their process specialization using the rabbit retinal Müller cell as an example of cytotopographic specialization of glial cells. Glia 2:250-259

36. Lundkvist A, Reichenbach A, Betsholtz C, Carmeliet $\mathrm{P}$, Wolburg H, Pekny M (2004) Under stress, the absence of intermediate filaments from Müller cells in the retina has structural and functional consequences. J Cell Sci 117:3481-3488

37. Lu YB, Iandiev I, Hollborn M, Körber N, Ulbricht E, Hirrlinger PG, Pannicke T, Wie EQ, Bringmann A, Wolburg H, Wilhelmsson U, Pekny M, Wiedemann P, Reichenbach A, Käs JA (2011) Reactive glial cells: increased stiffness correlates with increased intermediate filament expression. FASEB J 25:624-631

38. Tadayoni R, Massin P, Haouchine B, Cohen D, Erginay A, Gaudric A (2001) Spontaneous resolution of small stage 3 and 4 full-thickness macular holes viewed by optical coherence tomography. Retina 21:186-189

39. Privat E, Tadayoni R, Gaucher D, Haouchine B, Massin P, Gaudric A (2007) Residual defect in the foveal photoreceptor layer detected by optical coherence tomography in eyes with spontaneously closed macular holes. Am J Ophthalmol 143:814-819

40. Curcio CA, Sloan KRJ, Kalina RE, Hendrickson AE (1990) Human photoreceptor topography. J Comput Neurol 292:497-523 
41. Tornambe PE (2003) Macular hole genesis: the hydration theory. Retina 23:421-424

42. Smiddy WE, Flynn HW (2004) Pathogenesis of macular holes and therapeutic implications. Am J Ophthalmol 137:525-537
Publisher's Note Springer Nature remains neutral with regard to jurisdictional claims in published maps and institutional affiliations. 